\title{
Involvement of the Endocannabinoid System in the Ability of Long-Term Tricyclic Antidepressant Treatment to Suppress Stress-Induced Activation of the Hypothalamic-Pituitary-Adrenal Axis
}

\author{
Matthew N Hill', W-S Vanessa Ho ${ }^{2}$, Katia J Sinopoli', Victor Viau ${ }^{3}$, Cecilia J Hillard ${ }^{2}$ and Boris B Gorzalka*,' \\ 'Department of Psychology, University of British Columbia, Vancouver, BC, Canada; ${ }^{2}$ Department of Pharmacology and Toxicology, Medical \\ College of Wisconsin, Milwaukee, WI, USA; ${ }^{3}$ Department of Cellular and Physiological Sciences, University of British Columbia, Vancouver, \\ BC, Canada
}

\begin{abstract}
The efficacy of antidepressants has been linked in part to their ability to reduce activity of the hypothalamic-pituitary-adrenal (HPA) axis; however, the mechanism by which antidepressants regulate the HPA axis is largely unknown. Given that recent research has demonstrated that endocannabinoids can regulate the HPA axis and exhibit antidepressant potential, we examined the hypothesis that the endocannabinoid system is regulated by long-term antidepressant treatment. Three-week administration of the tricyclic antidepressant desipramine $(10 \mathrm{mg} / \mathrm{kg} / \mathrm{day})$ resulted in a significant increase in the density of the cannabinoid $\mathrm{CB}_{\text {। }}$ receptor in the hippocampus and hypothalamus, without significantly altering endocannabinoid content in any brain structure examined. Furthermore, chronic desipramine treatment resulted in a reduction in both secretion of corticosterone and the induction of the immediate early gene c-fos in the medial dorsal parvocellular region of the paraventricular nucleus of the hypothalamus (PVN) following a 5 min exposure to swim stress. Acute treatment with the $\mathrm{CB}_{\text {I }}$ receptor antagonist, $\mathrm{AM} 25 \mathrm{I}(\mathrm{I} \mathrm{mg} / \mathrm{kg})$, before exposure to swim stress, completely occluded the ability of desipramine to reduce both corticosterone secretion and induction of c-fos expression in the PVN. Collectively, these data demonstrate that $\mathrm{CB}_{\text {I }}$ receptor density in the hippocampus and hypothalamus is increased by chronic tricyclic antidepressant treatment, and suggest that this upregulation could contribute to the ability of tricyclic antidepressants to suppress stress-induced activation of the HPA axis.

Neuropsychopharmacology (2006) 3 I, 259 I-2599. doi: I 0. I038/sj.npp. I 30 I092; published online 10 May 2006
\end{abstract}

Keywords: desipramine; AM25I; depression; swim stress; c-fos; norepinephrine

\section{INTRODUCTION}

Major depression is a psychiatric disease that results in dramatic alterations in emotional, neurovegetative, and cognitive processes. The neurobiology of depression is not well understood; however, a large body of evidence convincingly demonstrates a critical role of the hypothalamicpituitary-adrenal (HPA) axis (Holsboer, 2000). Specifically, both corticotrophin releasing hormone (CRH) and cortisol are reported to be increased in the cerebrospinal fluid and plasma of depressed patients (Arborelius et al, 1999; Parker

*Correspondence: Dr BB Gorzalka, Department of Psychology, University of British Columbia, 2136 West Mall, Vancouver, BC, Canada V6TIZ4, Tel: + I 604822 2952, Fax: + I 604822 6923,

E-mail: bgorzalka@psych.ubc.ca

Received 6 January 2006; revised 24 March 2006; accepted 28 March 2006

Online publication: 3 April 2006 at http://www.acnp.org/citations/ Npp04030606000 I/default.pdf et al, 2003; Holsboer, 2000). Furthermore, the ability of glucocorticoid hormones to exert negative feedback on HPA axis activity appears to be deficient in depression, resulting in a feed-forward hyperactivation of this system (Parker et al, 2003; Holsboer, 2000). This enhanced output of the HPA axis appears functionally relevant to depression, as long-term antidepressant treatment attenuates this phenomenon in humans (De Bellis et al, 1993; Pariante et al, 2004; Greden et al, 1983; Michelson et al, 1997), and suppresses stress-induced activation of the HPA axis in other species (Reul et al, 1993; Connor et al, 2000; Holsboer and Barden, 1996; de Medeiros et al, 2005; Butterweck et al, 2001; Stout et al, 2002). The ability of antidepressants to suppress HPA axis hyperactivity has been shown to be coupled to their clinical efficacy (Appelhof et al, 2006; Young et al, 2004). Specifically, normalization of glucocorticoid feedback and hypersecretion is associated with clinical remission, and patients who do not exhibit normalization of this system exhibit a significantly higher tendency to experience 
depressive relapse and have a poorer long-term prognosis (Ribeiro et al, 1993; Greden et al, 1983; Zobel et al, 2001). These data demonstrate that the ability of antidepressants to regulate the HPA axis could be integral to the remission of depressive symptoms; however, the mechanism by which antidepressants exert this effect is currently not well understood.

Given the role of the HPA axis in depression, it is interesting to note that recent work has suggested a critical role for the endocannabinoid system in regulating HPA axis activation. Specifically, electrophysiological studies have demonstrated that $\mathrm{CB}_{1}$ cannabinoid receptors in the paraventricular nucleus of the hypothalamus (PVN) are located on glutamatergic terminals and gate excitatory activation of the CRH neurosecretory cells ( $\mathrm{Di}$ et al, 2003). These data predict that activation of $\mathrm{CB}_{1}$ receptors in the $\mathrm{PVN}$ would result in a suppression of HPA axis activity, whereas a disruption in endocannabinoid signaling would result in hyperactivity of the HPA axis. This hypothesis has received substantial support in vivo, as genetic or pharmacological disruption of endocannabinoid signaling results in exaggerated endocrine responses to stress, and conversely, inhibition of endocannabinoid uptake or metabolism attenuates stress-induced activation of the HPA axis (Patel et al, 2004; Barna et al, 2004).

As the endocannabinoid system can regulate HPA axis activity, and could play a role in both the pathophysiology and treatment of depression (Hill and Gorzalka, 2005a, b; Gobbi et al, 2005; Witkin et al, 2005), the present study was designed to examine whether chronic treatment with the tricyclic antidepressant desipramine regulates endocannabinoids and/or the $C_{1}$ receptor.

\section{METHODS}

\section{Subjects}

Seventy-day-old male Sprague-Dawley rats (approx. $285 \mathrm{~g}$ at the onset of the study) housed in groups of three in triple wire mesh caging were used in this study. Colony rooms were maintained at $21^{\circ} \mathrm{C}$, and on a $12 \mathrm{~h}$ light/dark cycle, with lights on at 0700. All rats were given ad libitum access to Purina Rat Chow and tap water. All treatments performed in this study were approved by the Animal Ethics Committee of the University of British Columbia and were consistent with the standards of the Canadian Council on Animal Care.

\section{Treatment Procedure}

For the biochemical studies, animals were divided into two treatment groups: one received $10 \mathrm{mg} / \mathrm{kg}$ desipramine (Sigma, Canada) in saline and the other an equivalent amount of saline alone. All subjects received daily intraperitoneal injections for 21 days; $18 \mathrm{~h}$ following the last injection, all subjects were rapidly decapitated. Prefrontal cortex (a tissue block composed of medial prefrontal cortex and anterior cingulate, which was anatomically defined as the area dorsal to the anterior olfactory nucleus and medial to the corpus callosum and claustrum formation), amygdala (composed of central, basolateral, and medial nuclei), hippocampus, and hypothalamus (a tissue block that was anatomically defined by a dorsal barrier of the top of the third ventricle and laterally by the striatum and fornix) were dissected out on ice, immediately frozen in liquid nitrogen, and stored at $-80^{\circ} \mathrm{C}$ until analysis.

For neuroendocrine studies, animals were divided into four treatment conditions: (1) saline-vehicle (1:1:8 Tween 80 : dimethyl sulfoxide: $0.9 \%$ saline); (2) $10 \mathrm{mg} / \mathrm{kg}$ desipramine-vehicle; (3) saline- $1 \mathrm{mg} / \mathrm{kg}$ AM251 (TocrisCookson, USA); (4) $10 \mathrm{mg} / \mathrm{kg}$ desipramine- $1 \mathrm{mg} / \mathrm{kg}$ AM251. AM251 was administered in the Tween vehicle and desipramine was administered in saline. All injections were given intraperitoneally in a volume of $1 \mathrm{ml} / \mathrm{kg}$ using $261 / 2^{\prime \prime}$ gauge needles. Rats were administered vehicle or $10 \mathrm{mg} / \mathrm{kg}$ desipramine injections for 21 days; on the 22nd day, the final injection of vehicle or desipramine was immediately preceded by an injection of $1 \mathrm{mg} / \mathrm{kg}$ AM251 or vehicle. Two cohorts of animals were prepared in these treatment conditions. One cohort was exposed to swim stress; the second cohort of animals was not exposed to swim stress to permit examination of the effects of these treatment conditions on basal activity of the HPA axis. At $1 \mathrm{~h}$ after the final injections, subjects were exposed to a $5 \mathrm{~min}$ swim stress session, which was performed in a cylindrical Plexiglas container, filled to a height of $30 \mathrm{~cm}$ with water at $21^{\circ} \mathrm{C}$. At $45 \mathrm{~min}$ following stressing, subjects were subjected to a brief tail bleed to obtain blood for analysis of plasma corticosterone. At $1 \mathrm{~h}$ following the tail bleed, all subjects were overdosed with sodium pentobarbital $(120 \mathrm{mg} / \mathrm{kg})$ and trans-cardially perfused with $4 \%$ paraformaldehyde. The brains were then fixed in paraformaldehyde overnight and stored in phosphate-buffered saline until sectioned for immunohistochemical analysis. These time points were based on previous studies in which the peak corticosterone secretion and expression of $c$-fos following exposure to the swim stress were determined (Connor et al, 2000; Duncan et al, 1996). Animals that were not exposed to swim stress were given injections, bled, and perfused at comparable time points to assess any effects of these treatments on basal activity of the HPA axis. This paradigm was chosen because, in rats, chronic administration of antidepressants is required to elicit the suppression of corticosterone and reduction in c-fos expression in the PVN (Connor et al, 1998, 2000; Duncan et al, 1996).

\section{Biochemical Analysis}

Brain sections were homogenized, membranes isolated, and $\mathrm{CB}_{1}$ receptor binding parameters determined as previously described (Hill et al, 2005a). For analysis of endocannabinoid content, brain regions were subjected to a lipid extraction process exactly as described previously (Patel et al, 2003). The content of the two primary endocannabinoids anandamide (AEA) and 2-arachidonylglycerol (2-AG) within lipid extracts was determined using isotope-dilution liquid chromatography-mass spectrometry as described previously (Patel et al, 2005a).

\section{Radioimmunoassay}

Blood was allowed to coagulate overnight at $4{ }^{\circ} \mathrm{C}$. The following morning, plasma was harvested by centrifugation at 12000 r.p.m. for $20 \mathrm{~min}$ and was stored at $-80^{\circ} \mathrm{C}$ until 
analysis. Plasma corticosterone levels were determined by radioimmunoassay as detailed previously (Hill et al, 2005b).

\section{Immunohistochemical Analysis}

Fixed brains were sliced coronally into $35 \mu \mathrm{m}$ coronal sections using a vibratome. Sections were washed in potassium phosphate-buffered saline (KPBS), incubated in a $0.4 \%$ peroxide bath, and thoroughly washed again in KPBS. Sections were then briefly exposed to $0.1 \%$ sodium borohydride solution, washed in KPBS, and incubated for $48 \mathrm{~h}$ at $4{ }^{\circ} \mathrm{C}$ in KPBS with $2 \%$ goat serum and $0.3 \%$ Triton $\mathrm{X}-100$ (loaded KPBS) containing polyclonal rabbit antisera against residues 4-17 of human fos protein (Oncogene Labs, Cambridge, MA, USA; at $1: 26000$ ). Sections were subsequently washed in KPBS and incubated in biotinylated, goat anti-rabbit secondary antibody $(1: 222)$ for $60 \mathrm{~min}$, washed again in KPBS, and transferred to a avidin-biotin complex solution (Vector Laboratories, Burlingame, CA, USA) for $60 \mathrm{~min}$. Tissue was then washed in KPBS, transferred to $1.0 \mathrm{M}$ sodium acetate, and developed using a diaminobenzidine reaction driven by glucose oxidase. Tissue was subsequently mounted, dehydrated, and coverslipped. Light-level images were captured using a Hamamatsu optical system coupled to a Macintosh computer running Open Lab imaging and measuring software (Quorum Technologies, Guelph, ON, Canada). Fos-ir cell counts were taken by an observer blind to animal status in regularly spaced $(150-\mu \mathrm{m})$ intervals through the rostrocaudal extent of the paraventricular cell group. Positive cells were identified as those expressing a black nuclear reaction product. Discrete localization of Fos-ir profiles to the dorsal medial parvocellular (neuroendocrine anterior pituitary regulating) population of the PVN (mpdPVN) was accomplished by limiting the region of interest to the area medial to the magnocellular population, lateral to the periventricular zone, and ventral to the dorsal cap, as has been carried out previously. This conservative analysis ensures that all slices are examined at the same rostral-caudal axis and also ensures that the region of interest is where all the CRH neurosecretory cells, which communicate to the anterior pituitary to stimulate ACTH, are amassed (Viau et al, 2005; Viau and Sawchenko, 2002). Cell number estimates were generated by counting bilaterally the number of Fospositive cells through the medial parvocellular cell population, averaged by dividing cell counts by slice number, and corrected for sampling frequency (one in five sections, 150 $\mu \mathrm{m}$ intervals) by multiplying this product by a factor of five. Furthermore, to ensure that any determinations were not artifacts of PVN area, we also performed density analysis, determining how many fos-ir cells were present per $\mathrm{mm}^{2}$ of the mpdPVN. Results thus represent estimates of the total number of Fos-positive cells per mpdPVN region as well as number of Fos-ir cells per $\mathrm{mm}^{2}$.

\section{Statistics}

Cannabinoid $\mathrm{CB}_{1}$ receptor binding parameters and endocannabinoid content were analyzed by a $t$-test comparing vehicle-treated animals with desipramine-treated animals. Analysis of the stress-induced hormonal and cellular effects was performed using a univariate analysis of variance, with drug treatment and swim exposure as fixed factors. Post hoc tests were performed using a Tukey's HSD test. Significance was established against an alpha value of 0.05 .

\section{RESULTS}

Chronic Treatment with the Tricyclic Antidepressant Desipramine Upregulates the $\mathrm{CB}_{1}$ Receptor in Key Regions of the Stress Axis

Animals that had been treated for 21 days with desipramine exhibited significant increases in the binding site density $\left(B_{\max }\right)$ of the cannabinoid $\mathrm{CB}_{1}$ receptor in the hippocampus $(t(5)=4.43, p<0.01)$ and the hypothalamus $(t(6)=3.76$, $p<0.01)$. There was no significant effect of desipramine treatment on the $B_{\max }$ of the $\mathrm{CB}_{1}$ receptor in the prefrontal cortex $(t(6)=2.20, p>0.05)$ or amygdala $(t(5)=0.31$, $p>0.05)$. Data regarding the effects of desipramine treatment on the $B_{\max }$ of the cannabinoid $\mathrm{CB}_{1}$ receptor can be seen in Figure 1. There was no significant effect of chronic desipramine treatment upon the affinity $\left(K_{\mathrm{d}}\right)$ of $\left[{ }^{3} \mathrm{H}\right] \mathrm{CP}$ 55,940 for the $\mathrm{CB}_{1}$ receptor in the prefrontal cortex $(t(6)=$ $-0.16, p>0.05$; vehicle: $0.27 \pm 0.04 \mathrm{nM}$ vs desipramine: $0.28 \pm 0.07 \mathrm{nM})$, the hippocampus $(t(5)=1.55, p>0.05$; vehicle: $1.14 \pm 0.14 \mathrm{nM} v s$ desipramine $1.67 \pm 0.28 \mathrm{nM})$, the hypothalamus $(t(6)=0.76, p>0.05$; vehicle: $2.21 \pm 1.24 \mathrm{nM}$ $v s$ desipramine: $2.87 \pm 0.85 \mathrm{nM})$, or the amygdala $(t(5)=$ $0.31, p>0.05$; vehicle: $1.7 \pm 0.86 \mathrm{nM} \quad v s$ desipramine: $0.82 \pm 0.27 \mathrm{nM})$.

Animals that had been treated with desipramine for 21 days did not exhibit any significant changes in prefrontal cortical AEA $(t(14)=0.10, p>0.05)$ or $2-A G$ content $(t(13)$ $=1.70, p>0.05)$; hippocampal AEA $(t(14)=0.52, p>0.05)$ or 2 -AG content $(t(13)=0.31, p>0.05)$; hypothalamic AEA $(t(11)=0.95, p>0.05)$ or $2-\mathrm{AG}$ content $(t(11)=0.15$, $p>0.05)$; or amygdalar AEA $(t(14)=1.11, p>0.05)$ or 2 -AG content $(t(14)=0.99, p>0.05)$. Data regarding the effects of chronic desipramine treatment on endocannabinoid content in these brain structures can be seen in Table 1 .

\section{Upregulation of the Endocannabinoid System Contributes to the Suppression of Stress-Induced Activation of the HPA Axis Elicited by Chronic Desipramine Treatment}

To examine whether the upregulation of the $\mathrm{CB}_{1}$ receptor following chronic desipramine treatment plays a functional role in the effects of this treatment on HPA axis responsivity, we determined whether acute blockade of the $\mathrm{CB}_{1}$ receptor affected swim stress-induced corticosterone release and $c$-fos expression in the mpdPVN. There was a significant interaction between drug treatment and exposure to swim stress on plasma corticosterone concentration $(\mathrm{F}(3,40)$ $=3.14, p<0.05)$, with a significant main effect of exposure to stress $(\mathrm{F}(1,40)=469.26, p<0.01)$, but no main effect of drug treatment $(\mathrm{F}(3,40)=1.45, p>0.05)$. Post hoc analyses revealed that exposure to swim stress increased plasma corticosterone $(p<0.01$ for all treatment conditions); however, chronic pretreatment with desipramine resulted in a significant reduction in plasma corticosterone following stress exposure compared to saline-treated, stressed rats $(p<0.04)$. Acute treatment with AM251 completely 

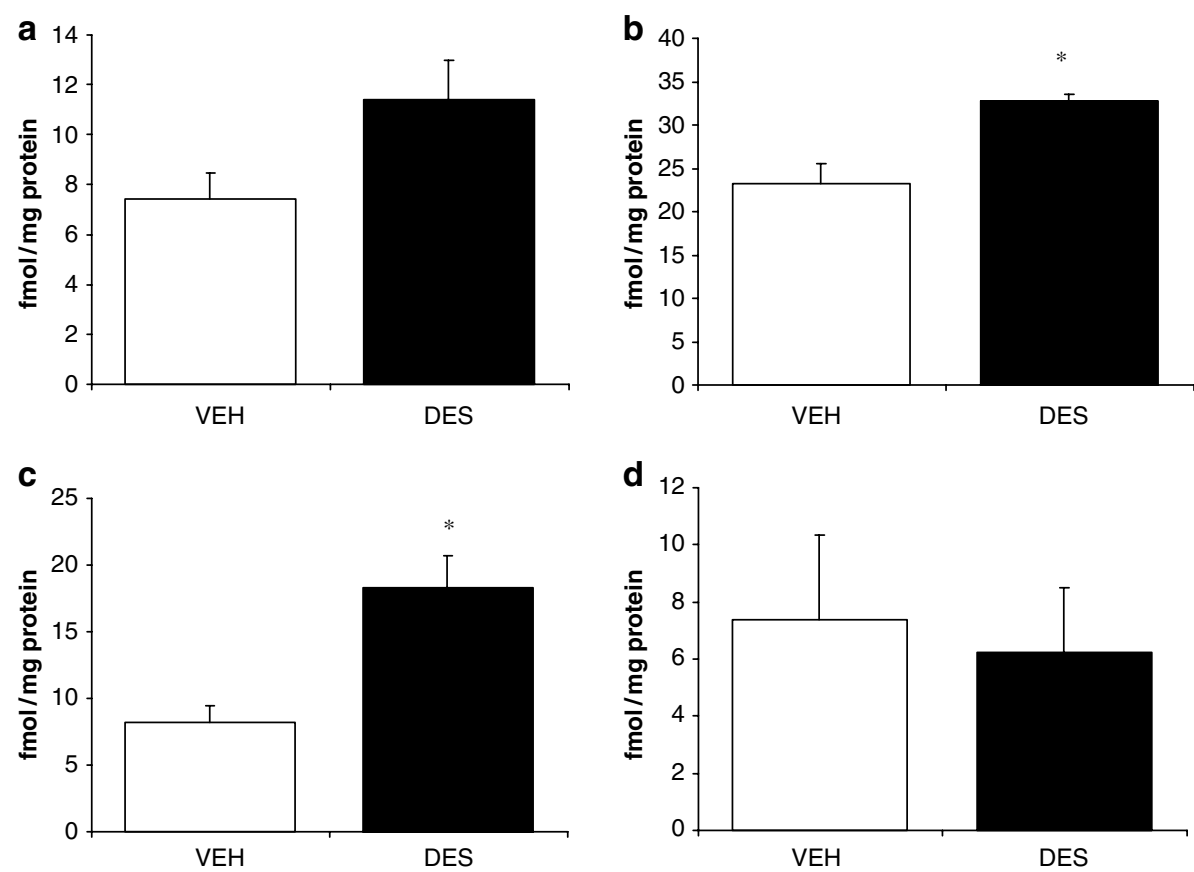

Figure I The effect of chronic desipramine (DES; $10 \mathrm{mg} / \mathrm{kg}$ ) treatment on the maximal binding $\left(B_{\max }\right)$ of the cannabinoid $C B_{1}$ receptor as measured by $\left[{ }^{3} \mathrm{H}\right] \mathrm{CP} 55,940$ binding in the (a) prefrontal cortex, (b) hippocampus, (c) hypothalamus, and (d) amygdala, relative to vehicle (VEH)-treated rats. Data are presented as mean values \pm SEM ( $n=3-4$ subjects/group). Significant differences $(p<0.05)$ are denoted by *.

Table I Effect of Chronic Desipramine (10 mg/kg) Treatment on Brain Regional Endocannabinoid Content

\begin{tabular}{lrr}
\hline & Control & Desipramine \\
\hline Prefrontal cortex & & \\
AEA (pmol/g tissue) & $9.99 \pm 0.56$ & $10.09 \pm 0.85$ \\
2-AG (nmol/g tissue) & $4.58 \pm 0.43$ & $5.66 \pm 0.46$ \\
& & \\
Hippocampus & & $23.25 \pm 0.84$ \\
AEA (pmol/g tissue) & $23.76 \pm 0.55$ & $8.41 \pm 0.37$ \\
2-AG (nmol/g tissue) & $8.27 \pm 0.22$ & \\
& & $2.42 \pm 0.31$ \\
Hypothalamus & & $7.93 \pm 0.71$ \\
AEA (pmol/g tissue) & $2.79 \pm 0.26$ & \\
2-AG (nmol/g tissue) & $7.81 \pm 0.52$ & $6.82 \pm 0.78$ \\
& & $8.68 \pm 0.79$ \\
Amygdala & & \\
AEA (pmol/g tissue) & & \\
2-AG (nmol/g tissue) & $7.56 \pm 0.81$ & \\
\hline
\end{tabular}

Desipramine treatment for 21 days did not change the content of either anandamide (AEA) or 2-arachidonylglycerol (2-AG) in any brain region examined. Data are presented as mean values \pm SEM ( $n=6-8$ subjects/group).

occluded the desipramine-induced reduction in plasma corticosterone $(p<0.05)$, whereas AM251 administration alone had no effect on the stress-induced increase in plasma corticosterone $(p>0.05)$. There was no effect of either desipramine or AM251 treatment on plasma corticosterone levels in animals that had not been exposed to the stressor. These data can be seen in Table 2 .
Table 2 Effect of Chronic Desipramine $(10 \mathrm{mg} / \mathrm{kg})$ Treatment and Acute Pharmacological Blockade of the Cannabinoid $\mathrm{CB}_{1}$ Receptor,

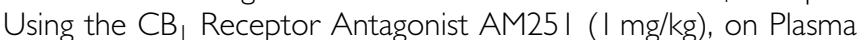
Corticosterone Levels Under Basal Conditions and Following Exposure to Swim Stress

\begin{tabular}{lrl}
\hline & No stress & Swim stress \\
\hline Plasma corticosterone $(n g / m l)$ & & \\
$\quad$ Saline-vehicle & $92.0 \pm 22.1$ & $537.4 \pm 19.3^{*}$ \\
Desipramine-vehicle & $138.2 \pm 31.8$ & $417.7 \pm 11.9^{*} \ddagger$ \\
Saline-AM25 | & $119.4 \pm 45.6$ & $541.0 \pm 16.7 *$ \\
Desipramine-AM25 | & $137.2 \pm 13.9$ & $536.9 \pm 32.4 *$ \\
\hline
\end{tabular}

Data are presented as mean values \pm SEM ( $n=5-7$ subjects/group). Significant differences between stress and no stress groups for each respective treatment $(p<0.05)$ are denoted by *; significant differences between desipramine-vehicle swim stress group and all other swim stress conditions $(p<0.05)$ are denoted by $\ddagger$.

With respect to number of fos-ir cells present in the mpdPVN, results paralleled the hormonal data. Two-way ANOVA revealed a significant interaction between exposure to stress and drug treatment $(\mathrm{F}(3,25)=5.00, p<0.01)$, with significant main effects of both stress exposure $(\mathrm{F}(1,25)$ $=235.71, p<0.01)$ and drug treatment $(\mathrm{F}(3,25)=8.98$, $p<0.01)$. Post hoc analyses demonstrated that exposure to swim stress significantly increased fos expression in the mpdPVN in all treatment groups (all $p$ 's $<0.01$ ); however, animals that had been pretreated with desipramine exhibited significantly lower levels of c-fos expression in the mpdPVN than all other groups exposed to stress (all $p$ 's $<0.01$ ). Acute treatment with AM251 prevented this reduction in fos-ir in the mpdPVN in desipramine-treated 


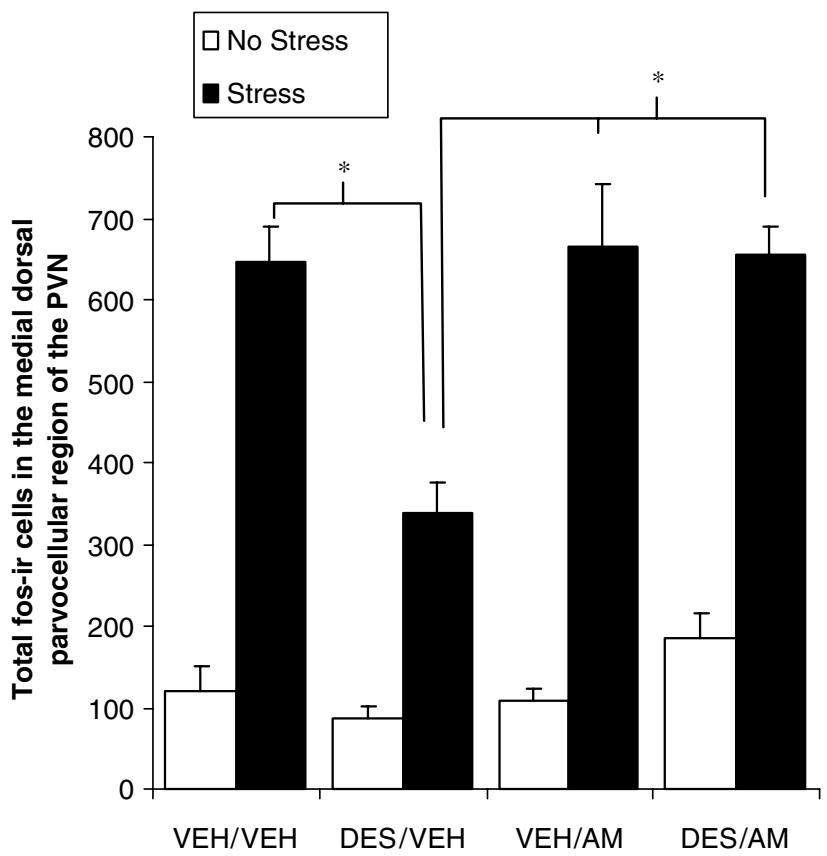

Figure 2 The effect of chronic administration of desipramine (DES; $10 \mathrm{mg} / \mathrm{kg}$ ), and the influence of acute cannabinoid $\mathrm{CB}_{\text {| }}$ receptor blockade through administration of AM25 I (AM; I mg/kg), on both basal and stressinduced elevations in the total number of fos immunoreactive-like (fos-ir) cells in the medial dorsal parvocellular population of the paraventricular nucleus (mpdPVN) of the hypothalamus. Data are presented as mean values \pm SEM ( $n=4-5$ subjects/group). Significant differences $(p<0.05)$ are denoted by *.

animals $(p<0.01)$. These data can be seen in Figure 2, and photomicrographs illustrating the changes in c-fos expression in the mpdPVN can be seen in Figure 3.

A comparable trend was seen in density measurements of fos-ir cells per $\mathrm{mm}^{2}$ of the mpdPVN. Two-way ANOVA of the $\mathrm{c}$-fos density measurements revealed a significant interaction between exposure to stress and drug treatment $(\mathrm{F}(3,25)=7.36, p<0.01$; data not shown $)$, with significant main effects of both stress exposure $(F(1,25)=316.01$, $p<0.01)$ and drug treatment $(\mathrm{F}(3,25)=14.30, p<0.01)$. As with total fos-ir cells in the mpdPVN, the density of fos-ir cells showed that all animals exposed to the swim stress exhibited a significant increase in fos-ir (all $p$ 's $<0.01$ ); however, those that had been pretreated with desipramine exhibited a significantly lower density of fos-ir cells $(p<0.01)$. The reduction in the density of fos-ir cells was elicited by chronic desipramine treatment in rats treated with AM251 $(p<0.01)$.

\section{DISCUSSION}

This study provides the first demonstration to date that chronic treatment with the tricyclic antidepressant desipramine produces an increase in the density of $\mathrm{CB}_{1}$ cannabinoid receptor binding sites in the hippocampus and hypothalamus without effects on either the binding affinity of the agonist $\left[{ }^{3} \mathrm{H}\right] \mathrm{CP} 55,940$ or tissue contents of the two major endocannabinoids in any brain structure examined. As both the hippocampus and hypothalamus are involved in processing and regulating responses to stress, these data suggest that chronic desipramine treatment could change stress responsivity as a result of changes in $\mathrm{CB}_{1}$ receptor signaling in these brain regions. These findings are intriguing given that chronic unpredictable stress, an animal model of depression, results in a significant reduction in $\mathrm{CB}_{1}$ receptor binding site density and a downregulation of the endocannabinoid 2-AG in the hippocampus (Hill et al, 2005a). This bidirectional regulation of hippocampal $\mathrm{CB}_{1}$ receptors by stress and antidepressants suggests that $\mathrm{CB} 1$ receptor/endocannabinoid signaling in the hippocampus could be relevant for the development and treatment of depression. Interestingly, long-term desipramine treatment did not affect endocannabinoid content in any brain structure examined, although brain regional endocannabinoid content is sensitive to stress exposure (Hill et al, 2005a; Patel et al, 2004, 2005b) and is affected by acute manipulation of monoamine receptor activity (Patel et al, 2003; Giuffrida et al, 1999).

The mechanism by which chronic tricyclic antidepressant treatment regulates $\mathrm{CB}_{1}$ receptor expression is currently unknown; however, previous studies have demonstrated that antidepressant treatment can increase receptor trafficking and upregulate membrane expression of receptors, such as the AMPA receptor (Martinez-Turrillas et al, 2002). The $\mathrm{CB}_{1}$ receptor is known to exist at both the membrane level and in intracellular endosomic stores, with the vast majority $(\sim 85 \%)$ of the receptor population typically existing in intracellular vesicles (Leterrier et al, 2004). Thus, the increase in $\mathrm{CB}_{1}$ receptor binding sites following tricyclic antidepressant treatment may be owing to an increase in receptor trafficking such that a higher proportion of $\mathrm{CB}_{1}$ receptors are active at the membrane site. This increase in active expression of the $\mathrm{CB}_{1}$ receptor may be an adaptive response elicited by treatment with desipramine. The primary pharmacological property of desipramine is its ability to inhibit norepinephrine reuptake and thus potentiate the synaptic action of norepinephrine (Frazer, 1997; Wong et al, 2000). Both in vivo and ex vivo work in rodent and human tissue has demonstrated that $\mathrm{CB}_{1}$ receptors in the hippocampus and hypothalamus negatively regulate noradrenergic neurotransmission (Tzavara et al, 2001; Schlicker et al, 1997). Thus, the upregulation of $\mathrm{CB}_{1}$ receptors in the hippocampus and hypothalamus seen in this study could be an adaptive response launched by the central nervous system to decrease noradrenergic transmission by increasing the density of presynaptic $\mathrm{CB}_{1}$ receptors, which in turn would reduce NE release and normalize the increased synaptic availability induced by desipramine treatment.

One common functional response to chronic antidepressant treatment, especially tricyclic antidepressants, is an attenuation of stress-induced activation of the HPA axis (Duncan et al, 1996; Connor et al, 2000; de Medeiros et al, 2005; Butterweck et al, 2001). To explore the functional relevance of the changes in the endocannabinoid system induced by chronic desipramine treatment, we examined the effects of acute blockade of the $\mathrm{CB}_{1}$ receptor with AM251 on the peak hormonal and cellular responses to stress following this antidepressant regimen. Chronic treatment with desipramine produced a significant reduction in both peak stress-induced increases in neuronal activation 

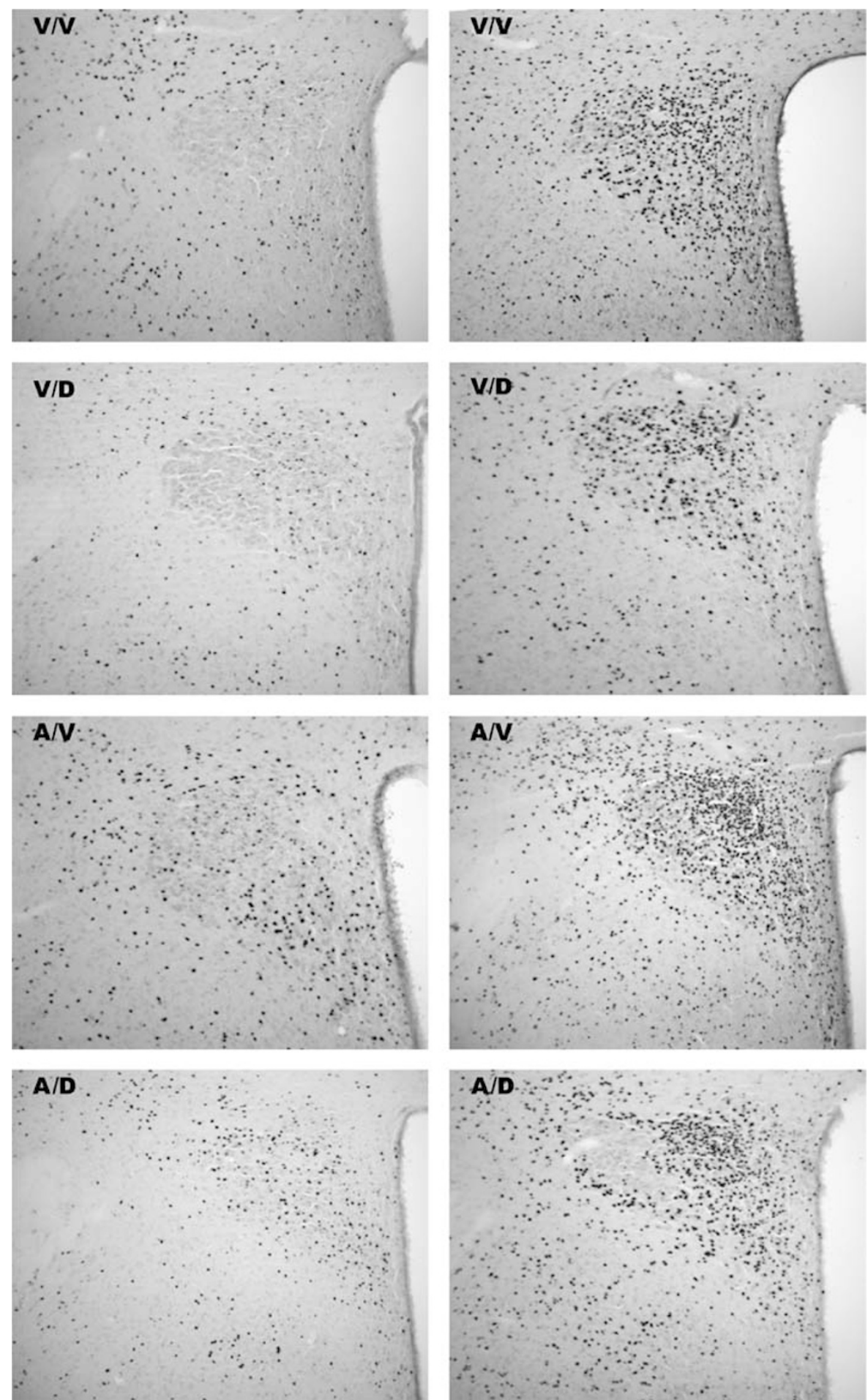

Figure 3 Representative photomicrographs of fos immunoreactivity in the mpdPVN under both basal conditions (left panel) and in response to swim stress exposure (right panel) $(V=$ vehicle; $D=$ desipramine; $A=A M 25 I)$.

within the mpdPVN and peak stress-induced increases in plasma corticosterone concentrations, as has been shown previously (Duncan et al, 1996; Connor et al, 2000). Acute treatment with AM251 completely occluded the effect of desipramine to reduce activation of the HPA axis. These data suggest that engagement of the endocannabinoid system is necessary for tricyclic antidepressants to suppress stress-induced activation of the HPA axis. However, we cannot rule out changes in the time course of the activation of the HPA axis; for example, AM251 treatment could delay the response or, alternatively, enhance its recovery. Future studies will examine these possibilities.

This interaction between antidepressants and the endocannabinoid system could occur at the level of the hypothalamus, a region in which desipramine increased $\mathrm{CB}_{1}$ receptor binding. Recent data have demonstrated that 
$\mathrm{CB}_{1}$ receptors in the PVN of the hypothalamus gate glutamatergic fibers, which activate the HPA axis (Di et al, 2003), which suggests that the endocannabinoid system can regulate glutamate-induced activation of the HPA axis. This hypothesis has received in vivo support from experiments demonstrating that genetic deletion of the $\mathrm{CB}_{1}$ receptor exacerbates stress-induced activation of the HPA axis, whereas enhancement of endocannabinoid signaling can attenuate stress-induced activation (Patel et al, 2004; Barna et al, 2004). Thus, the upregulation of the $\mathrm{CB}_{1}$ receptor in the hypothalamus seen in this study is consistent with suppression of stress-induced activation of the HPA axis following desipramine treatment. The suppression of corticosterone secretion following exposure to stress was accompanied by a reduction in neuronal activation of the mpdPVN of the hypothalamus, an area that contains all the CRH neurosecretory cells that regulate ACTH secretion through communication with the anterior pituitary. Although we did not assess CRH mRNA in this study, the region of interest we analyzed in the mpdPVN here is where all CRH neurosecretory cells are amassed (Viau and Sawchenko, 2002; Viau et al, 2005) suggesting that a suppression of stress-induced activation of CRH neurosecretory cells is likely mediating the effect of desipramine in this study. In support of this hypothesis, a recent report has demonstrated that reductions in stress-induced CRH transcription are associated with suppression of stressinduced peripheral corticosterone secretion following desipramine treatment (Conti et al, 2004). As such, the current data suggest that the ability of desipramine to suppress HPA axis activation could be through an upregulation of $\mathrm{CB}_{1}$ receptors in the mpdPVN, which regulate excitatory input to CRH neurosecretory cells, which in turn may lead to an increased suppression of stress-induced corticosterone secretion. However, given that $\mathrm{CB}_{1}$ receptors were also increased in the hippocampus, and the hippocampus is known to exert a potent role in regulation and feedback of the HPA axis (Jacobson and Sapolsky, 1991; Herman et al, 1998; Mueller et al, 2004), the possibility does exist that changes in the endocannabinoid system upstream of the mpdPVN could elicit a net reduction in activation of incoming afferents to the neurosecretory cells of the mpdPVN. Regardless of the locus of action, the current data suggest that the endocannabinoid system is involved in the effects of chronic desipramine administration to reduce HPA axis activation by stress.

These data also support our recently proposed hypothesis that the endocannabinoid system acts as a buffer against the effects of stress in the brain (Patel et al, 2005b). Specifically, repeated episodes of homotypic stress results in a habituation of the stress response that is accompanied by an increase in the tissue contents of endocannabinoid ligands in the limbic system and the hypothalamus, and acute treatment with a $\mathrm{CB}_{1}$ receptor antagonist can reverse habituation to repeated homotypic stress (Patel et al, 2004, 2005b). These data suggest that the endocannabinoid system acts to modulate or dampen activation of the neural stress axis (Patel et al, 2005b). We now extend this hypothesis to include that chronic exposure to desipramine (and perhaps other antidepressant drugs and therapies) also upregulates the endocannabinoid system, which, in turn, dampens the stress axis in a manner similar to habituation. This hypothesis is supported by recent clinical data demonstrating that plasma endocannabinoid content is increased in minor depression, but decreased in major depression, suggesting that successful upregulation of the endocannabinoid system can prevent the progression of stress into affective disease (Miller et al, 2005). Preclinical animal data also support this contention as transgenic mice that lack the $\mathrm{CB}_{1}$ receptor exhibit an increased susceptibility to the anhedonic effects of chronic stress, suggesting that this system may be integral to the development and maintenance of effective coping strategies to stress (Martin et al, 2002).

Given that the ability of antidepressants to regulate the HPA axis is tightly coupled to their clinical efficacy (Holsboer and Barden, 1996; Greden et al, 1983; Ribeiro et al, 1993; Zobel et al, 2001), these data suggest that upregulation of the endocannabinoid system is involved in the normalization of hypercortisolemia that accompanies remission of depression. These data also support the suggestion that the endocannabinoid system could serve as a suitable target for the development of novel antidepressants (Hill and Gorzalka, 2005a; Jiang et al, 2005; Gobbi et al, 2005), especially for melancholic depression (Hill and Gorzalka, 2005b), which exhibits a preferential response to tricyclic antidepressants and reliably exhibits hyperactivity of the HPA axis (Rush and Weissenburger, 1994; Bielski and Friedel, 1976; Gold and Chrousos, 2002).

\section{ACKNOWLEDGEMENTS}

This research was supported by an Independent Investigator NARSAD Award and R01 DA16967 to CJH; a Natural Sciences and Engineering Research Council of Canada (NSERC) operating grant to BBG; a Canadian Institute of Health Research operating grant to BBG and VV; and a Michael Smith Foundation for Health Research postgraduate trainee award and an NSERC Canadian Graduate Scholarship to MNH. We thank Larissa Froese, Anna Morrish, Maric Tse, Brenda Bingham, Patricia Lee, Craig Roelke, Sarah Meier, Jennifer Barker, and Wayne Yu for their technical assistance.

\section{REFERENCES}

Appelhof BC, Huyser J, Verweij M, Brouwer JP, van Dyck R, Fliers $\mathrm{E}$ et al (2006). Glucocorticoids and relapse of major depression (dexamethasone/corticotropin-releasing hormone test in relation to relapse of major depression). Biol Psychiatry 59: 696-701.

Arborelius L, Owens MJ, Plotsky PM, Nemeroff CB (1999). The role of corticotrophin-releasing factor in depression and anxiety disorders. J Endocrinol 160: 1-12.

Barna I, Zelena D, Arszovszki AC, Ledent C (2004). The role of endogenous cannabinoids in the hypothalamo-pituitary-adrenal axis regulation: in vivo and in vitro studies in $\mathrm{CB} 1$ receptor knockout mice. Life Sci 75: 2959-2970.

Bielski RJ, Friedel RO (1976). Prediction of tricyclic antidepressant response: a critical review. Arch Gen Psychiatry 33: 1479-1489.

Butterweck V, Winterhoff H, Herkenham M (2001). St John's wort, hypericin and imipramine: a comparative analysis of mRNA levels in brain areas involved in HPA axis control following short-term and long-term administration in normal and stressed rats. Mol Psychiatry 6: 547-564. 
Connor TJ, Kelliher P, Shen Y, Harkin A, Kelly JP, Leonard BE (2000). Effect of subchronic antidepressant treatments on behavioral, neurochemical and endocrine changes in the forced swim test. Pharmacol Biochem Behav 65: 591-597.

Connor TJ, Kelly JP, Leonard BE (1998). Forced swim test-induced endocrine and immune changes in the rat: effect of subacute desipramine treatment. Pharmacol Biochem Behav 59: 171-177.

Conti, AC, Kuo YC, Valentino RJ, Blendy JA (2004). Inducible cAMP early repressor regulates corticosterone suppression after tricyclic antidepressant treatment. J Neurosci 24: 1967-1975.

de Bellis MD, Gold PW, Geracioti Jr TD, Listwak SJ, Kling MA (1993). Association of fluoxetine treatment with reductions in CSF concentrations of corticotropin-releasing hormone and arginine vasopressin in patients with major depression. Am J Psychiatry 150: 656-657.

de Medeiros MA, Carlos Reis L, Eugenio Mello L (2005). Stress-induced c-Fos expression is differentially modulated by dexamethasone, diazepam and imipramine. Neuropsychopharmacology 30: 1246-1256.

Di S, Malcher-Lopes R, Halmos KC, Tasker JG (2003). Nongenomic glucocorticoid inhibition via endocannabinoid release in the hypothalamus: a fast feedback mechanism. J Neurosci 23: 4850-4857.

Duncan GE, Knapp DJ, Johnson KB, Breese GR (1996). Functional classification of antidepressants based on antagonism of swim stress-induced fos-like immunoreactivity. J Pharmacol Exp Ther 277: $1067-1089$.

Frazer A (1997). Antidepressants. J Clin Psychiatry 58(Suppl 6): 9-25.

Giuffrida A, Parsons LH, Kerr TM, Rodriguez de Fonseca F, Navarro M, Piomelli D (1999). Dopamine activation of endogenous cannabinoid signaling in dorsal striatum. Nat Neurosci 2: 258-263.

Gobbi G, Bambico FR, Mangieri R, Bortolato M, Campolongo P, Solinas $M$ et al (2005). Antidepressant-like activity and modulation of brain monoaminergic transmission by blockade of anandamide hydrolysis. Proc Natl Acad Sci USA 102: 1862018625.

Gold PW, Chrousos GP (2002). Organization of the stress system and its dysregulation in melancholic and atypical depression: high vs low CRH/NE states. Mol Psychiatry 7: 254-275.

Greden F, Gardner R, King D, Grunhaus L, Carroll J, Kronfol Z (1983). Dexamethasone suppression test in antidepressant treatment of melancholia. Arch Gen Psychiatry 40: 493-500.

Herman JP, Dolgas CM, Carlson SL (1998). Ventral subiculum regulates hypothalamo-pituitary-adrenocortical and behavioural responses to cognitive stressors. Neuroscience 86: 449-459.

Hill MN, Gorzalka BB (2005a). Pharmacological enhancement of cannabinoid $\mathrm{CB}_{1}$ receptor activity elicits an antidepressant-like response in the rat forced swim test. Eur Neuropsychopharmacol 15: 593-599.

Hill MN, Gorzalka BB (2005b). Is there a role for endocannabinoids in the pathophysiology and treatment of melancholic depression? Behav Pharmacol 16: 333-352.

Hill MN, Patel S, Carrier EJ, Rademacher DJ, Ormerod BK, Hillard CJ et al (2005a). Downregulation of endocannabinoid signaling in the hippocampus following chronic unpredictable stress. Neuropsychopharmacology 30: 508-515.

Hill MN, Sun JC, Tse MTL, Gorzalka BB (2005b). Alteration in serotonin receptor responsiveness following long-term cannabinoid treatment. Int J Neuropsychopharmacol (in press).

Holsboer F (2000). The corticosteroid receptor hypothesis of depression. Neuropsychopharmacology 23: 477-501.

Holsboer F, Barden N (1996). Antidepressants and hypothalamicpituitary-adrenocortical regulation. Endocr Rev 17: 187-205.

Jacobson L, Sapolsky R (1991). The role of the hippocampus in feedback regulation of the hypothalamic-pituitary-adrenocortical axis. Endocr Rev 12: 118-134.
Jiang W, Zhang Y, Xiao L, Van Cleemput J, Ji S-P, Bai G et al (2005). Cannabinoids promote embryonic and adult hippocampus neurogenesis and produce anxiolytic- and antidepressive-like effects. J Clin Invest 115: 3104-3116.

Leterrier C, Bonnard D, Carrel D, Rossier J, Lenkei Z (2004). Constitutive endocytic cycle of the $\mathrm{CB} 1$ cannabinoid receptor. J Biol Chem 279: 36013-36021.

Martin M, Ledent C, Parmentier M, Maldonado R, Valverde O (2002). Involvement of CB1 cannabinoid receptors in emotional behaviour. Psychopharmacology 159: 379-387.

Martinez-Turrillas R, Frechilla D, Del Rio J (2002). Chronic antidepressant treatment increases the membrane expression of AMPA receptors in rat hippocampus. Neuropharmacology 43: 1230-1237.

Michelson D, Galliven E, Hill L, Demitrack M, Chrousos G, Gold P (1997). Chronic imipramine is associated with diminished hypothalamic-pituitary-adrenal axis responsivity in healthy humans. J Clin Endocrinol Metab 82: 2601-2606.

Miller GE, Hill MN, Ho WSV, Gorzalka BB, Hillard CJ (2005). Bidirectional alterations in serum endocannabinoids in minor and major depression. Soc Neurosci Abstr 107: 3.

Mueller NK, Doglas CM, Herman JP (2004). Stressor-selective role of the ventral subiculum in regulation of neuroendocrine stress responses. Endocrinology 145: 3763-3768.

Pariante CM, Papadopoulos AS, Poon L, Cleare AJ, Checkley SA, English J et al (2004). Four days of citalopram increase suppression of cortisol secretion by prednisolone in healthy volunteers. Psychopharmacology 177: 200-206.

Parker KJ, Schatzberg AF, Lyons DM (2003). Neuroendocrine aspects of hypercortisolism in major depression. Horm Behav 43: 60-66.

Patel S, Carrier EJ, Ho WS, Rademacher DJ, Cunningham S, Reddy DS et al (2005a). The postmortal accumulation of brain $\mathrm{N}$-arachidonylethanolamine (anandamide) is dependent upon fatty acid amide hydrolase activity. J Lipid Res 46: 342-349.

Patel S, Rademacher DJ, Hillard CJ (2003). Differential regulation of the endocannabinoids anandamide and 2-arachidonylglycerol within the limbic forebrain by dopamine receptor activity. J Pharmacol Exp Ther 306: 880-888.

Patel S, Roelke CT, Rademacher DJ, Cullinan WE, Hillard CJ (2004). Endocannabinoid signaling negatively modulates stressinduced activation of the hypothalamic-pituitary-adrenal axis. Endocrinology 145: 5431-5438.

Patel S, Roelke CT, Rademacher DJ, Hillard CJ (2005b). Inhibition of restraint stress-induced neural and behavioural activation by endogenous cannabinoid signalling. Eur J Neurosci 21: $1057-1069$.

Reul JM, Stec I, Soder M, Holsboer F (1993). Chronic treatment of rats with the antidepressant amitriptyline attenuates the activity of the hypothalamic-pituitary-adrenocortical system. Endocrinology 133: 312-320.

Ribeiro SC, Tandon R, Grunhaus L, Greden JF (1993). The DST as a predictor of outcome in depression: a meta-analysis. $A m \mathrm{~J}$ Psychiatry 150: 1618-1629.

Rush AJ, Weissenburger JE (1994). Melancholic symptom features and DSM-IV. Am J Psychiatry 151: 489-498.

Schlicker E, Timm J, Zentner J, Gothert M (1997). Cannabinoid CB1 receptor-mediated inhibition of noradrenaline release in the human and guinea-pig hippocampus. Naunyn Schmiedebergs Arch Pharmacol 356: 583-589.

Stout SC, Owens MJ, Nemeroff CB (2002). Regulation of corticotropin-releasing factor neuronal systems and hypothalamic-pituitary-adrenal axis activity by stress and chronic antidepressant treatment. J Pharmacol Exp Ther 300: 1085-1092.

Tzavara ET, Perry KW, Rodriguez DE, Bymaster FP, Nomikos GG (2001). The cannabinoid CB(1) receptor antagonist SR141716A increases norepinephrine outflow in the rat anterior hypothalamus. Eur J Pharmacol 426: R3-R4. 
Viau V, Bingham B, Davis J, Lee P, Wong M (2005). Gender and puberty interact on the stress-induced activation of parvocellular neurosecretory neurons and corticotropin-releasing hormone messenger ribonucleic acid expression in the rat. Endocrinology 146: 137-146.

Viau V, Sawchenko PE (2002). Hypophysiotropic neurons of the paraventricular nucleus respond in spatially, temporally, and phenotypically differentiated manners to acute $v s$ repeated restraint stress. J Comp Neurol 445: 293-307.

Witkin JM, Tzavara ET, Nomikos GG (2005). A role for cannabinoid CB1 receptors in mood and anxiety disorders. Behav Pharmacol 16: 315-331.
Wong EH, Sonders MS, Amara SG, Tinholt PM, Piercey MF, Hoffmann WP et al (2000). Reboxetine: a pharmacologically potent, selective, and specific norepinephrine reuptake inhibitor. Biol Psychiatry 47: 818-829.

Young EA, Altemus M, Lopez JF, Kocsis JH, Schatzberg AF, DeBattista C et al (2004). HPA axis activation in major depression and response to fluoxetine: a pilot study. Psychoneuroendocrinology 29: 1198-1204.

Zobel AW, Nickel T, Sonntag A, Uhr M, Holsboer F, Ising M (2001). Cortisol response in the combined dexamethasone/CRH test as predictor of relapse in patients with remitted depression: a prospective study. J Psychiatr Res 35: 83-94. 